\title{
Exosomes as renal inductive signals in health and disease, and their application as diagnostic markers and therapeutic agents
}

\author{
Mirja Krause, Anatoliy Samoylenko and Seppo J. Vainio * \\ Biocenter Oulu, Infotech Oulu, Developmental Biology Lab, Faculty of Biochemistry and Molecular Medicine, Center for Cell \\ Matrix Research, University of Oulu, Oulu, Finland
}

OPEN ACCESS

Edited by:

Tomer Avidor-Reiss,

University of Toledo, USA

Reviewed by:

Bas W. M. Van Balkom University Medical Center Utrecht,

Netherlands

Gloria Alvarez-Llamas, Instituto de Investigación Sanitaria de la Fundación Jiménez Díaz, Spain

*Correspondence: Seppo J. Vainio seppo.vainio@oulu.fi

Specialty section: This article was submitted to Cell Growth and Division, a section of the journal Frontiers in Cell and Developmental Biology

Received: 01 July 2015 Accepted: 05 October 2015 Published: 20 October 2015

Citation: Krause M, Samoylenko A and Vainio SJ (2015) Exosomes as renal inductive signals in health and disease, and their application as diagnostic markers and therapeutic agents. Front. Cell Dev. Biol. 3:65

doi: 10.3389/fcell.2015.00065
Cells secrete around 30-1000 nm membrane-enclosed vesicles, of which members of the subgroup between 30 and $100 \mathrm{~nm}$ are termed exosomes (EXs). EXs are released into the extracellular space and are widely present in body fluids and incorporated mRNA, miRNA, proteins, and signaling molecules. Increasing amounts of evidence suggest that EXs play an important role not only in cell-to-cell communication but also in various physiological and disease processes. EXs secreted by kidney cells control nephron function and are involved in kidney diseases and cancers. This makes them potential targets for diagnostic and therapeutic applications such as non-invasive biomarkers and cell-free vaccines and for use as drug delivery vehicles. This review provides an overview on the known roles of EXs in kidney development and diseases, including renal cancer. Additionally, it covers recent findings on their significance as diagnostic markers and on therapeutic applications to renal diseases and cancers. The intention is to promote an awareness of how many questions still remain open but are certainly worth investigating.

Keywords: extracellular vesicles, exosomes, kidney development, diagnostic markers, therapeutics, renal disease, renal cancer

\section{INTRODUCTION}

Cells from various organisms, including all the eukaryotes and many prokaryotes, release extracellular vesicles of different types into their environment. The term exosomes (EXs) describes those vesicles which are of endosomal origin. They are small $(30-100 \mathrm{~nm})$ membrane-enclosed vesicles which are secreted by various cell types, and can be found in biological fluids such as blood, semen, saliva, and urine (reviewed by Raposo and Stoorvogel, 2013; Yanez-Mo et al., 2015). Initially these were considered to take part in the cell's waste management but evidence has accumulated that they are instrumental in intercellular and system (humoral)-level communication in organisms. The striking property of EXs is that they can transfer important compounds such as membrane and cytosolic proteins, lipids, mRNA, miRNA (Valadi et al., 2007), and even DNA between cells. Thus, they provide a novel but apparently evolutionary ancient platform for cell-to-cell and tissue interactions (Valadi et al., 2007).

Even though the putative developmental role of EXs remains in most respects unclear, it is emerging that at least many of the key developmental signaling pathways are coordinated by EXs (Raposo and Stoorvogel, 2013; Urbanelli et al., 2013). Kidney cells, for instance, appear to release vesicles presumably in a developmentally regulated manner, and the currently available data suggest 
that EXs may initiate and regulate organogenesis. In addition, they may also take part in processes such as regeneration and the development of diseases such as cancer. Interestingly, kidneyderived vesicles may also have an impact on the cells of certain other organs (Grange et al., 2011) and even the immune system. The aim of this review is to summarize the roles that have been demonstrated for EXs in kidney development and disease, especially in kidney tumorigenesis.

\section{EXOSOMES AS RENAL INDUCTIVE SIGNALS, DIAGNOSTIC MARKERS, DISEASE, AND THERAPEUTIC AGENTS}

\section{Biogenesis and Signal Transduction}

The biogenesis of EXs is a complex intracellular process that forms part of the endosomal cell sorting machinery, in which an array of regulatory factors has been identified (Stoorvogel et al., 2002; Théry et al., 2002; Kowal et al., 2014). Upon the initiation of EX assembly an early endosome is formed by an inward budding of the cellular membranes via endocytosis. In association with this budding the endosomal membrane undergoes a second inward folding to generate further smaller vesicles inside the endosomal lumen. The process is collectively called the formation of multivesicular bodies (MVB; Figure 1).
The machinery known as the Endosomal Sorting Complex Required for Transport (ESCRT) is involved in the formation of MVBs, although it also entails an ESCRT-independent mechanism involving proteins such as tetraspanins and lipids (for details, see recent reviews by Hanson and Cashikar, 2012; Henne et al., 2013; Colombo et al., 2014; Kowal et al., 2014). The assembled MVBs can then fuse either with lysosomes, leading to their degradation, or alternatively with the cellular plasma membrane (PM), which releases their vesicles, called from here on exosomes (EXs), into the extracellular milieu of the cell. The fusion of MVBs with the PM was first described in the hematopoietic system, namely in differentiating red blood cells (Pan and Johnstone, 1983), and thereafter in several other cell types such as B-cells, T-cells, dendritic cells (Escola et al., 1998; Zitvogel et al., 1998; Blanchard et al., 2002), mast cells (Raposo et al., 1997), and yeast cells (Henne et al., 2013). The biogenesis of EXs has also been described in epithelial cells, including those of the kidney (Knepper and Pisitkun, 2007), being the cells that line the renal tubule lumen (Pisitkun et al., 2004).

On their release EXs interact with a recipient cell in several ways. A schematic overview of the biogenesis of EXs and how they enter target cells and interact with them is depicted in Figure 1. As one mode of interaction, EXs bind to the target cell via membrane receptors such as the Major histocompatibility complex (MHC) that mediates binding to T-cells (Denzer et al.,

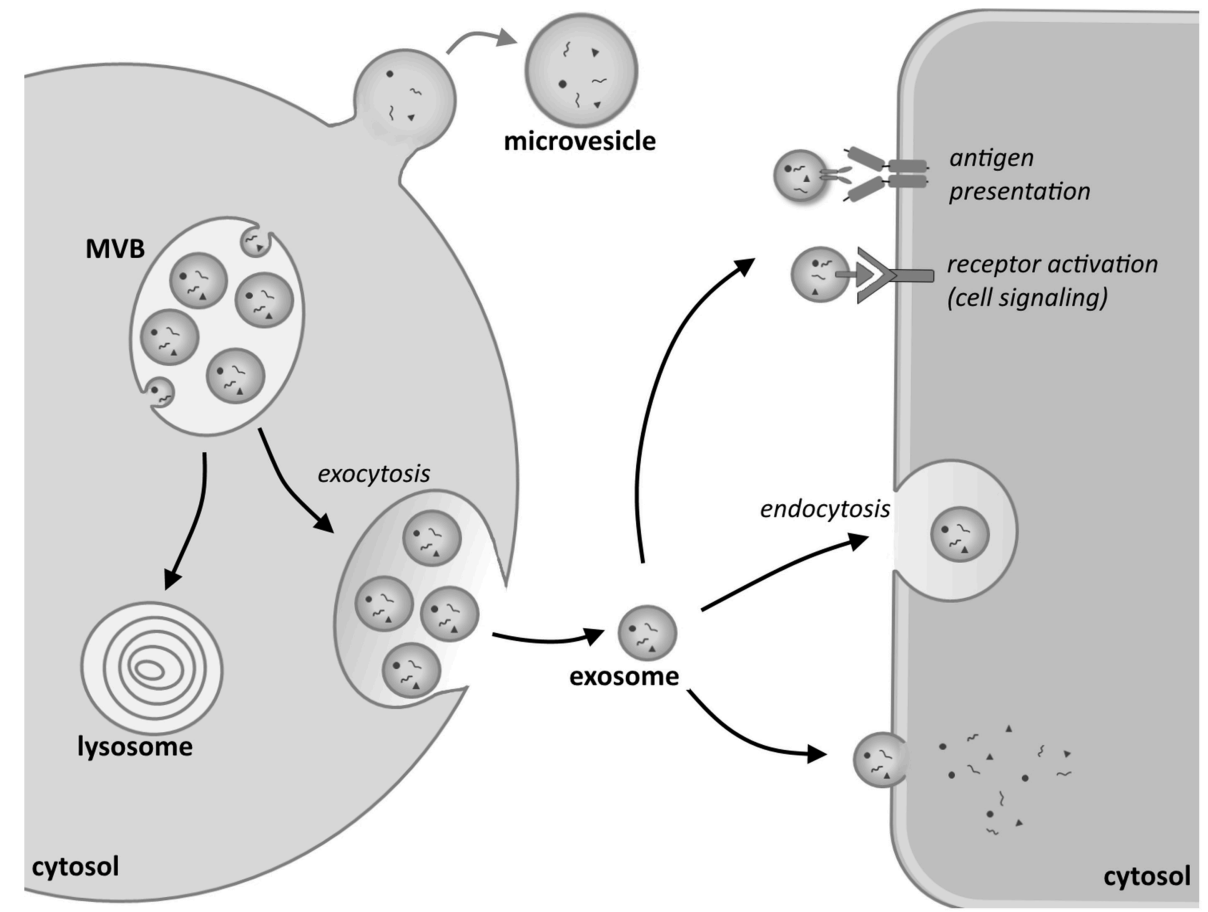

FIGURE 1 | Biogenesis and uptake of exosomes. Inward budding of the membrane of an endosomal vesicle in the cytosol of the donor cell leads to the formation of multivesicular bodies (MVBs). These can either turn into lysosomes, whereupon their content will be degraded, or fuse with the plasma membrane, releasing their content into the extracellular environment. These vesicles are called exosomes. By contrast, larger microvesicles are formed when the cell membrane directly buds outwards, giving rise to micelles. Exosomes can interact with recipient cells in various ways. Signaling can be initiated by an antigen-antibody interaction in the recipient cell or by the activation of a receptor on the cell membrane of the target cell. Exosomes can also be taken up by endocytosis or fuse directly with the plasma membrane. Upon fusion their cargo is released into the cytosol of the target cell. 
2000; Nolte-'t Hoen et al., 2009). Another way in which EXs bind is via recognition of the ligands on their lipid bilayer by means of specific cell surface receptors. Indeed, many common ligand/receptor pairs such as recognition by integrins or tetraspanins have been identified. The capacity of an EX to bind to a given cell depends to a great deal, however, on the cellular content, and also the characteristics of the donor cell from which the EXs originated. The most prominent binding mechanisms have been reviewed recently by Colombo et al. (2014) and are therefore, not reviewed here. Besides receptormediated binding, the entry of EXs into a target cell may involve endocytosis (Morelli et al., 2004), phagocytosis (Feng et al., 2010; Christianson et al., 2013; Yanez-Mo et al., 2015), or pinocytosis (Parolini et al., 2009; Théry et al., 2009; Yanez-Mo et al., 2015). These processes can also be receptor-mediated, aided by several other proteins such as dynamin (Fitzner et al., 2011) and clathrin (Mulcahy et al., 2014; Tian et al., 2014), which regulate entry. In the case of kidney-derived cells such as COS-7, the cells seem to internalize EX through lipid raft-mediated endocytosis which is negatively regulated by caveolin-1 (Svensson et al., 2013). It is currently poorly understood whether EX uptake mechanisms are common or specific to each cell type (Gildea et al., 2014). Furthermore, there is also some debate as to how widely certain EXs can influence cell behavior (White et al., 2006; Svensson et al., 2013).

\section{Exosomes in Kidney Physiology}

The currently available data suggest that the extracellular vesicles are coupled to normal development and various diseases. Given that EXs contain key regulatory signals such as mRNA and miRNA and can transfer them from one cell type to another, they may have a profound influence on target cell homeostasis (Montecalvo et al., 2012; Stoorvogel, 2012; Tomasoni et al., 2012; Zhang et al., 2015b). The capacity of EXs to transport miRNA is of particular importance when considering participation in developmental control in general (Tang et al., 2007). Even though it still remains unknown whether EXs indeed play a crucial role in morphogenesis, the current results suggest that at least urinary EXs, besides being involved in the secretion of senescent proteins as exocytic waste (Pisitkun et al., 2004; Knepper and Pisitkun, 2007) may also have other roles (van Balkom et al., 2011; Fang et al., 2013). In the light of current data, the systemic serum containing EXs cannot cross the kidney filter within the glomerulus under normal conditions (Pisitkun et al., 2004; Gildea et al., 2014), but whether this changes in the presence of kidney anomalies remains open.

Proteomic studies of urinary EXs have identified proteins that characterize certain nephron segments such as the glomerulus and Henle's loop. A summary is given in Table $\mathbf{1}$ (Pisitkun et al., 2004; Miranda et al., 2010; Dear et al., 2013). The available data suggest that most, if not all, of the nephron cell types have the capacity to secrete vesicles. EXs may play an important role in mediating cell-to-cell communication along the nephron with potential significance for kidney performance, and it has been shown that the function of the EXs within the nephron may be the adaptation of nephron function to changes in physiology, i.e., in homeostasis. This possibility is based on the observation that different segments of the nephron secrete and take up EXs differentially (Dimov et al., 2009). Renal EXs can also transfer functional molecules such as aquaporin-2 between cells (Street et al., 2011), although their uptake capacity becomes restricted in the fully matured adult kidney. This is probably caused by accumulation of the tubular Tamm-Horsfall protein, which prevents contacts between EXs and the tubular luminal cells unless this protein is degraded locally (van Balkom et al., 2011). Hence, the luminal epithelial cells of the nephron apparently secrete the EXs found in urine. Furthermore, proteins which are specifically associated with the urinary bladder and prostate gland have also been found in urine (Musante et al., 2014), although further studies are needed to provide conclusive evidence of this.

When considering the embryonic kidney and the potential of EXs for taking part in its developmental programming, many of the proteins known to control organogenesis, including growth factors (see the recent review by Krause et al., 2015) are in fact found in the EXs that have been characterized from a variety of cell lines (Table 2). The Wnt-family members and their signal transduction pathway are critical for kidney development, and interestingly, several Wnt proteins and their downstream factors such as $\beta$-catenin are associated with EXs and can also mediate activation of the pathway (Table 2; Zhang et al., 2015a). It can be speculated that a panel of key developmental signals may also be associated with and transported to the target cells via EXs during kidney development.

If this is the case, then EXs constitute a new critical mechanism in the control of kidney development by transferring and integrating key inductive signals. Thus, their presence during kidney development should be explored further: Which cells secrete EXs under which environmental conditions, and do these EXs populations differ one from another? Further analysis should then reveal details of their content, transport mechanisms and physiological roles during kidney development.

The putative role of EXs has recently been explored in MadinDarby canine kidney cells (MDCK; Kwon et al., 2014). When these cells are subjected to the hepatocyte growth factor (HGF) their proliferation is stimulated and eventually tubular cysts form. Changes in the expression of a specific $G$ protein-coupled receptor, GPRC5B, are associated with EXs being secreted by these cells. This protein is also up-regulated in tubulogenesis, while the exosomal delivery of GPRC5B induces extracellular signal-regulated kinase 1/2 (Erk1/2). As the GPRC5B is expressed in the ureteric bud of the embryonic kidney, this may suggest that it also plays a role in organogenesis.

\section{The Role of Exosomes in Kidney Regeneration and Diseases}

While the role of kidney-derived EXs in physiological processes remains poorly investigated, EXs have been found to exercise beneficial or adverse functions in the development of several kidney diseases (Borges et al., 2013a; Fang et al., 2013). For example, vesicles derived from mesenchyme stem cells (MSCs) or endothelial stem cells can promote kidney regeneration (Borges et al., 2013a). The positive impact of MSCs on both acute and chronic kidney injury (AKI and CKI) was first attributed to 
TABLE 1 | Proteins found in human urinary exosomes that are specific to or enriched in given regions of the kidney.

\begin{tabular}{|c|c|c|c|c|c|c|}
\hline Kidney region & Gene symbol & Full gene name & Species & $\begin{array}{l}\text { Exosome } \\
\text { sample }\end{array}$ & $\begin{array}{l}\text { Identified } \\
\text { molecule }\end{array}$ & Associated diseases \\
\hline \multirow[t]{4}{*}{ Glomerulus } & PODXL & Podocalyxin-like Protein & Homo sapiens & Urine & Protein & Diabetic nephropathy \\
\hline & NPHS2 & Podocin & Homo sapiens & Urine & mRNA & $\begin{array}{l}\text { Focal segmental glomerulosclerosis, } \\
\text { nephrotic syndrome [MIM: 600995] }\end{array}$ \\
\hline & LGALS1 & Galectin-1 & Homo sapiens & Urine & mRNA & - \\
\hline & HSPG2 & Heparan Sulfate Proteoglycan 2 & Homo sapiens & Urine & mRNA & $\begin{array}{l}\text { Schwartz-Jampel syndrome type } 1 \\
\text { [MIM: 255800] }\end{array}$ \\
\hline \multirow[t]{10}{*}{$\begin{array}{l}\text { 1st convoluted } \\
\text { tubule }\end{array}$} & gp330 precursor & Glycoprotein 330 Precursor & Homo sapiens & Urine & Protein & $\begin{array}{l}\text { Renal aminoglycoside accumulation } \\
\text { and nephrotoxicity, Donnai-Barrow } \\
\text { syndrome }\end{array}$ \\
\hline & CUBN & $\begin{array}{l}\text { Cubilin (Intrinsic } \\
\text { Factor-Cobalamin Receptor) }\end{array}$ & Homo sapiens & Urine & $\begin{array}{l}\text { Protein, } \\
\text { mRNA }\end{array}$ & $\begin{array}{l}\text { Megaloblastic anemia } 1 \text { [MIM: } \\
\text { 261100] }\end{array}$ \\
\hline & AQP1 & Aquaporin1 & Homo sapiens & Urine & $\begin{array}{l}\text { protein, } \\
\text { mRNA }\end{array}$ & $\begin{array}{l}\text { Nephrogenic diabetes insipidus, } \\
\text { Aquaporin } 1 \text { deficiency, Colton-Null } \\
\text { [MIM: 110450] }\end{array}$ \\
\hline & LRP2 & Megalin & Homo sapiens & Urine & mRNA & Heymann nephritis, proteinuria \\
\hline & CA4 & Carbonic Anhydrase 4 & Homo sapiens & Urine & mRNA & $\begin{array}{l}\text { Diabetic nephropathy, Proximal renal } \\
\text { tubular acidosis [MIM: 114760] }\end{array}$ \\
\hline & ANPEP & Alanyl Aminopeptidase & Homo sapiens & Urine & protein & Hypertension [MIM: 151530] \\
\hline & NAPSA & Napsin A & Homo sapiens & Urine & Protein & Kidney carcinoma, renal neoplasms \\
\hline & CLCN 5 & Chloride Channel Protein 5 & Homo sapiens & Urine & mRNA & Dent's disease \\
\hline & GGT1 & $\gamma$-glutamyltransferase & Homo sapiens (male) & Urine & Protein & - \\
\hline & APN & Aminopeptidase N & Homo sapiens (male) & Urine & Protein & - \\
\hline \multirow[t]{7}{*}{ Henle's loop } & AQP1 & Aquaporin 1 & Homo sapiens & Urine & Protein & $\begin{array}{l}\text { Nephrogenic diabetes insipidus, } \\
\text { Aquaporin } 1 \text { deficiency, Colton-Null } \\
\text { [MIM: 110450] }\end{array}$ \\
\hline & UMOD & Uromodulin & Homo sapiens & Urine & Protein & $\begin{array}{l}\text { Hyperuricemic nephropathy, } \\
\text { Medullary cystic kidney disease-2 } \\
\text { (MCKD2) [MIM: 603860], familial } \\
\text { juvenile hyperuricemic nephropathy } \\
\text { (FJHN) [MIM: 16200] }\end{array}$ \\
\hline & THP & Tamm-Horsfall Protein & Homo sapiens (male) & Urine & Protein & $\begin{array}{l}\text { Mckd2 [mim: 603860], fjhn [mim: } \\
\text { 16200] }\end{array}$ \\
\hline & CD9 & $\begin{array}{l}\text { Cluster of Differentiation } \\
\text { (Tetraspanin) }\end{array}$ & Homo sapiens (male) & Urine & Protein & - \\
\hline & BDKRB1 & Bradykinin B1 Receptor & Homo sapiens & Urine & mRNA & - \\
\hline & CALCR & Calcitonin Receptor & Homo sapiens & Urine & mRNA & Kidney stone disease \\
\hline & SCNN1D & $\begin{array}{l}\text { Amiloride-sensitive Sodium } \\
\text { Channel Subunit Delta }\end{array}$ & Homo sapiens & Urine & mRNA & - \\
\hline $\begin{array}{l}\text { 2nd convoluted } \\
\text { tubule }\end{array}$ & SLC12A3 (NCC) & $\begin{array}{l}\text { Thiazide-sensitive } \mathrm{Na}-\mathrm{Cl} \\
\text { Cotransporter }\end{array}$ & Homo sapiens & Urine & Protein & Gitelman syndrome [MIM: 263800] \\
\hline \multirow[t]{5}{*}{ Collecting ducts } & AQP2 & Aquaporin 2 & Homo sapiens & Urine & $\mathrm{mRNA}$ & $\begin{array}{l}\text { Nephrogenic diabetes insipidus type } \\
1 \text { [MIM: 222000] [MIM: 125800] }\end{array}$ \\
\hline & ATP6V1B1 & V-ATPase B1 Subunit & Homo sapiens & Urine & mRNA & $\begin{array}{l}\text { Distal renal tubular acidosis [MIM: } \\
\text { 267300] }\end{array}$ \\
\hline & SLC12A1 & $\begin{array}{l}\text { Kidney-specific Na-K-Cl } \\
\text { Symporter }\end{array}$ & Homo sapiens & Urine & mRNA & $\begin{array}{l}\text { Bartter-Syndrome type 1, 2, } 3 \text { [MIM: } \\
601678,241200,607364]\end{array}$ \\
\hline & MUC1 & Mucin-1 & Homo sapiens (male) & Urine & Protein & $\begin{array}{l}\text { Renal cell carcinoma, Medullary cystic } \\
\text { kidney disease type } 1 \text { (MCKD1) } \\
\text { [MIM:174000] }\end{array}$ \\
\hline & $\mathrm{RHCG}$ & Rh type C glycoprotein & Homo sapiens (male) & Urine & Protein & - \\
\hline
\end{tabular}

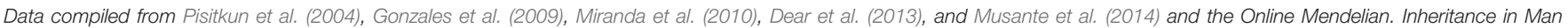
$\mathrm{OMIM}^{\circledR}$ website (http://Www.omim.org/, see MIM numbers for reference). 
TABLE 2 | Genes of importance during kidney development found in exosomes of various origins.

\begin{tabular}{|c|c|c|c|c|c|c|}
\hline $\begin{array}{l}\text { Gene } \\
\text { symbol }\end{array}$ & Full gene name & Species & Exosome sample & $\begin{array}{l}\text { Identified } \\
\text { molecule }\end{array}$ & References & $\begin{array}{l}\text { ExoCarta ID } \\
\text { (Mathivanan and } \\
\text { Simpson, 2009) }\end{array}$ \\
\hline Wnt4 & $\begin{array}{l}\text { Wingless-type MMTV Integration } \\
\text { Site Family, Member } 4\end{array}$ & Homo sapiens & $\begin{array}{l}\text { Umbelical cord } \\
\text { mesenchymal stem } \\
\text { cells }\end{array}$ & protein & Zhang et al., 2015a & No \\
\hline Wnt11 & $\begin{array}{l}\text { Wingless-type MMTV Integration } \\
\text { Site Family, Member } 11\end{array}$ & Mus musculus & Mast cells & mRNA & Valadi et al., 2007 & ExoCarta_22411 \\
\hline \multirow[t]{3}{*}{ Notch2 } & $\begin{array}{l}\text { Neurogenic locus notch homolog } \\
\text { protein } 2\end{array}$ & Homo sapiens & Ovarian cancer cells & Protein & Liang et al., 2013 & ExoCarta_4853 \\
\hline & & Homo sapiens & Colorectal cancer cells & Protein & Demory Beckler et al., 2013 & ExoCarta_4853 \\
\hline & & Bos taurus & Milk & Protein & Reinhardt et al., 2013 & ExoCarta_513730 \\
\hline BMP4 & Bone Morphogenetic Protein 4 & Homo sapiens & Colorectal cancer cells & Protein & Demory Beckler et al., 2013 & ExoCarta_652 \\
\hline FGFR1 & Fibroblast Growth Factor receptor 1 & Homo sapiens & Ovarian cancer cells & Protein & Liang et al., 2013 & ExoCarta_2260 \\
\hline \multirow[t]{4}{*}{ OSR1 } & Oxidative Stress responsive 1 & Homo sapiens & Ovarian cancer cells & Protein & Liang et al., 2013 & ExoCarta_9943 \\
\hline & & Homo sapiens & Thymus & Protein & Skogberg et al., 2013 & No \\
\hline & & Homo sapiens & Urine & Protein & Gonzales et al., 2009 & No \\
\hline & & Rattus norwegicus & Reticulocytes & Protein & Carayon et al., 2011 & ExoCarta_316064 \\
\hline \multirow[t]{2}{*}{ WT1 } & Wilms Tumor 1 Homolog & Mus musculus & Mast cells & mRNA & Valadi et al., 2007 & ExoCarta_22431 \\
\hline & & & & & Ranghino et al., 2014 & No \\
\hline$\beta$-catenin & Cadherin-associated protein beta & Mus musculus & Dendritic cells & Protein & Chairoungdua et al., 2010 & No \\
\hline
\end{tabular}

their role in directly replacing renal tubular cells, but later it became clear that these cells rather provide paracrine support for endogenous regeneration (Biancone et al., 2012). At present the role of MSCs has been assigned in part to the secretion of EXs (Camussi et al., 2010; Biancone et al., 2012; Borges et al., 2013a), e.g., in that MSC-derived EXs can enhance regeneration of the rat kidney epithelium when injured by ischemia-reperfusion (Gatti et al., 2011). This EX-mediated recovery involves cell-to-cell transfer of mRNAs and/or microRNAs and may be connected with the inhibition of renal cell apoptosis and the stimulation of tubular epithelial cell proliferation. Moreover, by reducing the acute injury, the EXs also protected the rats from later CKI development 6 months after the operation (Gatti et al., 2011).

Other studies have reported a regenerative potential in microvesicles (MVs) produced by bone marrow MSCs in glycerol-induced (Bruno et al., 2009), cisplatin-induced (Bruno et al., 2012), and gentamicin-induced (Reis et al., 2012) AKI models via a mechanism dependent on RNA delivery. Here the protective effect of EXs was mainly ascribed to an increase in surviving tubular cell proliferation (Bruno et al., 2009; Reis et al., 2012) and a decrease in tubular epithelial cell apoptosis (Bruno et al., 2009, 2012; Reis et al., 2012). These effects are thought to occur via the up-regulation of anti-apoptotic genes and down-regulation of genes involved in the execution phase of cell apoptosis (Bruno et al., 2012).

It has also been found that the development of chronic tubular injury is inhibited by multiple injections of MVs, while the effect of a single injection was not sufficient to prevent CKI (Bruno et al., 2012). Like bone marrow MSC-derived EXs, human umbilical cord MSC-derived EXs also demonstrated a protective effect on cisplatin-induced nephrotoxicity in vivo and in vitro, whereas human lung fibroblast-derived EXs did not (Dorronsoro and Robbins, 2013; Zhou et al., 2013a). Zhou et al. (2013a) demonstrated that these EXs can reduce cisplatin-mediated renal oxidative stress and apoptosis in rats in vivo and increase the proliferation of renal tubular epithelial NRK-52E cells in culture. They also showed that human umbilical cord MSC-derived EXs can reduce Bax (bcl-2-like protein 4) level and increase Bcl-2 (B-cell lymphoma 2) in order to inhibit apoptosis and stimulate Erk1/2, thereby increasing proliferation after cisplatin-induced injury in the kidney. Another group has shown that EXs isolated from peripheral blood-derived endothelial progenitor cells can prevent AKI in an ischemia-reperfusion rat model (Cantaluppi et al., 2012). In this case the miRNAs that modulate proliferation, angiogenesis and apoptosis were found to be responsible for the protective effects of EXs.

Kidney epithelial cells are another source of the EXs involved in kidney regeneration. It was found that administration of the epithelium-derived exosomal ATF3 (activating transcription factor 3) mRNA attenuates ischemia/reperfusion-induced kidney injury by inhibiting monocyte chemotactic protein-1 (MCP-1)induced macrophage infiltration (Chen et al., 2014b). While all the above-mentioned studies demonstrate beneficial effects of EXs on kidney regeneration, it was found on the other hand that EXs produced by injured proximal tubular epithelial cells in a murine model of hypoxic kidney fibrosis after unilateral ureteral obstruction can initiate tissue repair/regenerative responses and activate fibroblasts, leading to fibrosis (Borges et al., $2013 b)$. Fibroblast proliferation and the production of matrix proteins were particularly dependent on EXs delivering TGF- $\beta 1$ (transforming growth factor $\beta 1$ ) mRNA (Borges et al., 2013b).

Interestingly, certain in vitro studies published more than 20 years ago demonstrated that renal brush border-derived MVs about $100 \mathrm{~nm}$ in diameter can induce and promote calcium 
oxalate crystallization (Nagasawa et al., 1992; Anderson et al., 2010), which is one of the features of nephrolithiasis (kidney stone formation), a pathological kidney condition leading to fibrosis and chronic renal failure (Anderson et al., 2010).

Since, the endothelial cells are connected to the control of blood flow, pressure and clotting, they are prime targets when considering the development of EX-based therapies, and also the treating of renal diseases (van Balkom et al., 2011). It has been shown that circulating levels of endothelial-derived MVs are significantly higher in chronic renal failure patients than in healthy subjects (Faure et al., 2006). Moreover, blood levels of these MVs correlate with endothelial dysfunction and arterial stiffness in end-stage renal failure hemodialysis patients (Amabile et al., 2005). In contrast to endothelium-derived MVs, those produced by platelets or erythrocytes do not seem to be connected with endothelial dysfunction (Amabile et al., 2005). In another study it was found that the number of endothelialderived microparticles was inversely correlated with brachial artery and aortic laminar shear stress values in end-stage renal disease patients with a high cardiovascular risk (Boulanger et al., 2007).

It may be assumed that the action of cell-damaging agents such as low shear stress and increased arterial stiffness contributes to endothelial apoptosis through a substantial release of endothelial MVs (Amabile et al., 2005; Boulanger et al., 2007). The pathogenetic effects of EXs and other circulating microparticles in promoting vascular calcification and sclerosis in chronic kidney disease (CKD) are nevertheless not yet clearly defined (Anderson et al., 2010; Fang et al., 2013). Rather surprisingly, Neal et al. (2011) found that the levels of circulating miRNAs in patients with different stages of chronic kidney failure, including those receiving hemodialysis treatment, were reduced by comparison with patients having mild renal impairment or normal renal function. This observation might be explained by the fact that many circulating miRNAs are bound to Argonaute 2-containing protein complexes (Arroyo et al., 2011) or to high-density lipoproteins (Vickers et al., 2011) rather than within EXs. It has been demonstrated in a rat model of CKD induced by $5 / 6$ nephrectomy that the administration of conditioned medium from embryonic MSC has a therapeutic effect, whereas MSC-derived EXs tested in the same experimental setting showed no protective effect on the kidney (van Koppen et al., 2012).

\section{Exosomes in Kidney Cancer}

Although tumor cells secret large amounts of various MVs that enter the blood and other body fluids (Lee et al., 2011; Azmi et al., 2013), the isolation of cancer EXs from patients remains a serious problem due to the lack of specific markers that can distinguish cancer-derived from non-cancer-derived EXs. One such marker that has been identified recently is glypican1, detected on EXs derived from the serum of patients with pancreatic cancer but not on EXs from healthy subjects or subjects with chronic pancreatitis (Melo et al., 2015). Various biological roles have been proposed for EXs in cancer, such as the expulsion of key proteins and miRNA from cells, the removal of anti-cancer drugs and the release of signaling and regulatory molecules (Lee et al., 2011; Azmi et al., 2013). The properties of EXs may also enable them to take part in the control of cell proliferation, cell survival, angiogenesis, metastasis and immune response (Azmi et al., 2013; Fang et al., 2013). EX-released factors promote stromal remodeling and hypoxia-mediated epithelial mesenchyme transformation, which is critical for the evolution of cancer (Nieto, 2011). EXs can also stimulate the proliferation of fibroblasts by causing a desmoplastic reaction, and they can induce immune escape mechanisms by suppressing antigen-specific immune responses and by up-regulating immunosuppressive cell differentiation and the functioning of these cells (Azmi et al., 2013; Minciacchi et al., 2015). For these reasons EXs form a critical aspect of tumorigenesis.

Much less is known at present about the roles of EXs in kidney tumorigenesis, however. The relevant findings are that the vesicles released by renal carcinoma stem cells (rCSCs) derived from a tumor-bearing patient can trigger angiogenesis and promote lung metastasis when studied with the SCID (immunocompromised severe combined immunodeficient) mouse model (Grange et al., 2011). Grange et al. (2011) showed that rCSCs are secreted by a subset of tumor-initiating cells characteristically expressing the mesenchymal stem cell marker CD105, and that EXs derived from these rCSCs were able to stimulate the growth and invasiveness of normal HUVEC (human umbilical vein endothelial cells). In addition, these EXs increased the formation of capillary-like structures in culture and in induced vessel formation when cells treated with them were grafted into SCID mice.

More detailed molecular characterization of the CD105positive EXs pointed to significant differences in mRNA and miRNA content as compared with EXs that were negative for CD105. Consistent with their properties, the rCSC-derived EXs have mRNAs that encode for proangiogenic factors such as vascular endothelial growth factor (VEGF), fibroblast growth factor (FGF), angiopoietin-1, ephrin A3, and matrix metalloproteinases (MMP)-2 and -9. Similarly, these were reported to be absent from the CD105-negative tumor cellderived EXs. In addition to these findings, miRNAs that have been reported to be involved in biological processes such as the control of transcription, cell adhesion and cell proliferation were enriched in CD105-positive EXs (Grange et al., 2011, 2014).

Another indication that EXs derived from kidney cancer cells may be involved in the cancerous state and its severity, including the formation of metastases, came from the work of Tauro et al. (2013), who performed a proteomic analysis by comparing EXs released by normal and oncogenic H-Ras (21D1) transfected MDCK cells. While the control and 21D1-MDCK cell-derived EXs were similar in their morphology, the 21D1derived EXs had high levels of proteases, annexins, integrins, and other secreted proteins which are typically associated with the formation of premetastatic niches. The ability of primary cancer to make changes in normal tissue located in a pre-metastatic niche prior to the arrival of metastasizing cells is an important feature that facilitates sustained cancer growth (Wels et al., 2008). 
The role of EXs in the "education" of normal cells toward a pro-metastatic phenotype has been demonstrated not only for renal cell carcinoma but also for other cancers, including melanomas (Peinado et al., 2012) and breast cancer (Fong et al., 2015). Elsewhere, the transfection of MDCK cells with oncogenic $\mathrm{H}$-Ras has been found to induce the release of EXs that contain factors known to control nuclear assembly, transcription, splicing, and translation. The most abundant protein in the 21D1-derived EXs was the Y-box-binding protein (YBX1), which is a DNA and RNA- binding transcription factor involved in DNA replication, DNA repair, transcription, pre-mRNA splicing, and mRNA translation (Eliseeva et al., 2011).

Several studies have been conducted employing 786-0 human renal adenocarcinoma cells and targeted EXs in carcinogenesis (Zhang et al., 2013; Chen et al., 2014a; Du et al., 2014). Like the rCSC-derived EXs (Grange et al., 2011) the 786-0-derived ones promote tubulogenesis in HUVECs (Human umbilical vein endothelial cells; Zhang et al., 2013), and it has been speculated that the pro-angiogenic effect of these renal EXs may be mediated via down-regulation of hepaCAM (hepatic and glial cell adhesion molecule), a hepatocyte cell adhesion molecule, and up-regulation of VEGF. In turn, it has been shown that the EXmediated down-regulation of hepaCAM expression is in effect mediated by Akt phosphorylation connected with the enhanced renal carcinoma cell proliferation (Jiang et al., 2014). Collectively, the 786-0-derived EXs enhance cell migration, invasion and chemokine receptor type 4 (CXCR4) and MMP-9 expression and concurrently reduce the adhesion of 786-0 cells (Chen et al., 2014a).

A comprehensive report on the influence of EXs on renal carcinoma 786-0 cells has been published recently by Du et al. (2014), who investigated the putative effects of EXs released by human Wharton's jelly mesenchyme stem cells (hWJ-MSCs). These EXs promoted cell proliferation, cell migration, and progression of the cell cycle from G0/G1 to the S phase and the $\mathrm{HGF} / \mathrm{c}-\mathrm{Met}$, Akt, and Erk1/2 pathways in these cells. Moreover, the hWJ-MSCs-derived EXs stimulated tumorigenesis in the 7860 -cells and also enhanced tumor size. At the molecular level, the EXs induced cyclin D1, MMP-2, and MMP-9 expression in a $\mathrm{BALB} / \mathrm{c}$ nude mouse model (Du et al., 2014). Meanwhile, RNase pre-treatment abrogated these exosomal effects, indicating that the RNA delivered via EXs serves as a crucial mediator (Du et al., 2014).

Little is known as to whether the cells in various organs take up the cancer-derived EXs selectively. Rana et al. (2012) found that small differences in the EX-tetraspanin complexes that originated from different rat tumor cell lines greatly influenced the cell type to which the EXs were targeted in vitro or in vivo. When tetraspanin-8+ EXs were monitored after $24 \mathrm{~h}$ of injection they had been taken up by the pancreas and lung cells, whereas certain large vessels and the kidneys showed a lower abundance of such EXs. Moreover, the liver and gut cells were for the most part negative. These data thus suggest some target cell selectivity among EXs that are secreted in vivo.

Interestingly, EXs engineered to express a chimeric tetraspanin-8 in which the N-terminal region was swapped for a domain from the CD9 protein were readily taken-up by kidney cells but not by other organs, whereas EXs engineered to contain tetraspanin- 8 that was fused to an integrin $\beta 4$ was targeted preferentially to lung, kidney and gut cells. It is significant that also within an organ, EXs seem to be taken up preferentially by specific cell types depending on the exosomal protein content. One indication of this is the fact that tetraspanin-8; integrin $\beta+$ fusion EX products could be identified in only the kidney glomeruli (Rana et al., 2012).

There are several reports stating that EXs produced by kidney tumor cells are coupled to cancer-associated immune suppression (Yang et al., 2013; Diao et al., 2015; Gu et al., 2015). As an example of this, EXs purified from human kidney adenocarcinoma ACHN cells inhibited proliferation and induced apoptosis of Jurkat-immortalized T-cells while reducing in vitro interleukin-2 (IL-2), IL-6, IL-10 and interferon$\gamma$ production (Yang et al., 2013). In the light of these findings, the authors proposed that the Fas ligand within the tumorderived EXs must be responsible for exosomally induced T-cell death.

There is considerable evidence that EXs play a role in renal tumor progression in vivo. The survival of mice inoculated with renal adenocarcinoma Renca cells, which go on to generate tumors, was reduced to some degree in the presence of Rencaderived EXs in the assay ( $\mathrm{Gu}$ et al., 2015), and similar data have been reported by Diao et al. (2015), leading them to propose that the heat shock protein HSP70 present in EXs derived from cancer cells promotes the immunosuppressive activity of myeloid-derived suppressor cells (MDSCs), possibly via an increase in Stat3, a signal transducer and activator of transcription 3-phosphorylation.

Besides suppressing the immune system, EXs can also do exactly the opposite. Certain tumor-derived EXs induce an immune response. This suggests that EXs may even offer opportunities for developing individualized tumor immunotherapies (Greening et al., 2015). Given the fact that tumor-derived EXs also contain immunosuppressive molecules that reduce their immunogenicity, it is important to learn in detail how these properties are regulated, opening new avenues for valuable therapeutics. Along these lines, EXs that are secreted by IL-12-expressing RC-2 human renal cancer cells exhibited greater anti-tumor effects than EXs derived from "wild type" renal cells or cytocine-supplemented IL-12 alone (Zhang et al., 2010). Such IL-12-containing EXs efficiently induced cell proliferation, the release of interferon-gamma and the specific cytotoxic effects of T-cells derived from cultured human peripheral blood cells.

It is also of interest that the mice that had tumors derived either from the mouse myeloid leukemia line WEHI3B or renal carcinoma Renca cells survived longer if they had been vaccinated beforehand with the EX-loaded dendritic cells from the tumor (Gu et al., 2015). In other words, the tumor cell-derived EXs seemed to be superior to the tumor lysates as a source of antigen. Interestingly, the immunosuppressive features of EXs do not detract from their capacity to serve as an antigen source for the dendritic cells (Gu et al., 2015). These properties make the EXs very promising components for the development of novel cancer therapies. 


\section{Kidney/Urinary Exosomes as Diagnostic Biomarkers and Therapeutic Agents}

EXs have a great potential for use as valuable diagnostic biomarkers, especially in the case of monitoring kidney malfunction. Since, many reviews have been published on the analysis of urinary EXs and their potential as diagnostic markers for kidney disease, injury, and transplant rejection, this topic will be covered in the present review only briefly (Knepper and Pisitkun, 2007; Dimov et al., 2009; Dear et al., 2013; Properzi et al., 2013; Musante et al., 2014; Ranghino et al., 2014; Salih et al., 2014).

As discussed, the urinary EX components can be assigned to specific nephron segments, the glomerulus, the proximal/distal tubule, Henle's loop and the collecting duct (Table 1; Pisitkun et al., 2004; Miranda et al., 2010; Dear et al., 2013; Musante et al., 2014). Many of these proteins can be associated with certain diseases, but they are not all necessarily linked directly to the kidney. The level of GPRC5B in the urinary EXs correlates with $\mathrm{AKI}$, so that its values are elevated in cases of AKI by comparison with normal healthy subjects (Kwon et al., 2014), making GPRC5B a candidate diagnostic marker for AKI. Furthermore, levels of Fetuin-A were also found to be elevated in patients suffering from AKI (Zhou et al., 2006).

The review by Ranghino et al. (2014) summarizes several suitable urinary exosomal biomarkers for glomerular and tubular damage, including Wilms Tumor 1 Homolog (WT1), ATF3, and Neutrophil Gelatinase-Associated Lipocalin (NGAL). WT1 was found in urinary exosomes of patients who suffer from focal segmental glomerulosclerosis (FSGS; Zhou et al., 2008, 2013b) and in most diabetic patients (Kalani et al., 2013). ATF3 is another marker for AKI alongside Fetuin A and GPRC5B (Zhou et al., 2008). NGAL levels were elevated in patients with delayed graft function after kidney transplantation (Alvarez et al., 2013), and several protein markers have also been found in cases of diabetic nephropathy (Zubiri et al., 2014) and prostate (Lu et al., 2009; Mitchell et al., 2009) and urine bladder cancer (Smalley et al., 2008; Blackwell et al., 2014).

Some markers that classify a person as healthy have also been identified, and these may be of diagnostic value in cases of kidney regeneration. Promonin-1 (CD133) serves as such a marker, for example, as it is lost in the urine at the end stage of renal disease (Dimuccio et al., 2014), and additional markers have been defined for a panel of kidney diseases that include diabetic nephropathy (Musante et al., 2014), cardio-renal syndrome (Gonzalez-Calero et al., 2014), autosomal-dominant polycystic kidney disease (ADPKD; Fang et al., 2013; Ben-Dov et al., 2014) and Gitelman's and Bartter syndromes (Corbetta et al., 2015), as well as for following the organ-acceptance after a kidney transplantation (Alvarez et al., 2013).

In 2007 the group led by Jan Löttvall found that EXs carry different functional RNA species (Valadi et al., 2007). Renal mRNA levels have been used in the past as prognostic markers for kidney diseases (Eikmans et al., 2003), but this required an invasive kidney biopsy. Analysis of the protein and RNA content of urinary EXs provides a non-invasive alternative for evaluating changes in renal gene and protein expression, and it has been found that several exosomal microRNAs isolated from urine are suitable markers for certain kidney diseases. One study showed that exosomal miR-145 and miR-130a levels were elevated in patients with diabetic nephropathy, while levels of miR-155 and miR-424 were down-regulated (Barutta et al., 2013). Further studies with a larger group of patients would be necessary to confirm these results.

Several miRNA markers of CKD/renal fibrosis have been identified. Levels of exosomal miR-29a, miR-29c, miR-200b, and miR-200c were down-regulated in patients with moderate-tosevere fibrosis (Lv et al., 2013), but not in cases with mild fibrosis. The same paper also demonstrates that miR-29c provides indicators of renal function and the histological degree of fibrosis, making it the most prominent candidate for a biomarker of CKD, while (Lv et al., 2014) showed that the exosomal mRNA level of CD2-associated protein (CD2AP) was down-regulated in CKD patients, and even more so in patients with a more severe disease. Both of these reports not only identified disease markers, but also demonstrated that the level of miRNA/mRNA present in urinary EXs provides an opportunity to define the progression of the disease.

Protocols for analyzing exosomes and isolating RNA from them still have to be optimized further in order to yield unbiased, reliable results. Furthermore, it still needs to be ascertained whether levels of exosomal mRNA can also reflect levels of the proteins used as biomarkers for kidney diseases. The same RNA and protein markers as were used in the past when a kidney biopsy was performed might not apply to exosomal RNA and protein levels, as is supported by the fact that little equivalence was found between the exosomal and cellular RNAs of exosome-producing cells (Skog et al., 2008; Mittelbrunn et al., 2011; Koppers-Lalic et al., 2014). This implies an underlying mechanism for the targeted loading of certain RNA species into EXs, in contrast to the loading of the most abundant cellular RNA into EXs in order to discard it. Future studies will have to elucidate the sorting mechanisms responsible for this process. Nonetheless, it is this fact that makes EXs especially interesting, as mRNAs and miRNAs can influence gene expression in the recipient cell and providing the EXs with their therapeutic potential.

One therapeutic strategy would be that RNA-bearing EXs would deliver their cargo to specific malfunctioning target cells and could restore damaged or deregulated protein production. Several studies have shown that exosomes shuttle functional miRNA and influence the gene expression levels of target cells (Pegtel et al., 2010; Montecalvo et al., 2012; Chen et al., 2014c).

Another promising feature of EXs is to serve as a noncytotoxic drug delivery system. The challenge still lies in loading the drugs onto the EXs without imperiling their biological properties (Suntres et al., 2013). Different methods for loading a defined cargo onto EXs have been established, as recently reviewed (Johnsen et al., 2014). This is a possible way of developing novel therapeutics to treat various diseases. Some examples exist of studies which are currently in clinical trial phase I.

One such investigation concerns the potential application of EXs to deliver curcumin (which has proved to have biological activity) to colon cancer tissue (clinical trial no. NCT01294072), 
while another uses EXs as a vaccine, administering dendritic cellderived EXs (CSET 1437) loaded with antigen to lung cancer patients in order to activate their innate and adaptive immunity during therapy (clinical trial no. NCT01159288). Furthermore, the potential application of EXs to the treatment of kidney diseases is being explored. As described in Section The Role of Exosomes in Kidney Regeneration and Diseases above, various groups have shown that MSCs have a paracrine effect on acute and chronic kidney diseases (Gatti et al., 2011; van Balkom et al., 2011; Fang et al., 2013) in which soluble factors such as those associated with the secreted vesicles have a positive influence on cell behavior and promote the initiation of recovery. The potential of EXs for use in cell-free therapy applications has been summarized recently (Vishnubhatla et al., 2014) and will not be discussed here in detail. It is clear, however, that EXs from various cells such as MSCs and cancer cells have a great potential as novel therapeutic tools, and they can be expected to have a significant impact on the development of diagnostics and new treatments, for kidney diseases among others.

\section{CONCLUSIONS}

It has become generally accepted for the moment that EXs are present in a wealth of body fluids and are not only a cellular waste system as was thought earlier. Collectively, they may represent a newly identified but apparently ancient humoral system controlling homeostasis and disease, and they also provide a useful bank of biomarkers for a variety of diseases and may raise the value of urine as a non-invasive diagnostic component in medical practice. The analysis of urinary EXs not only provides us with prognostic disease markers, but might also make it possible to differentiate between diseases which display similar symptoms. Furthermore, certain data have shown that it is possible to estimate the severity of a disease, and hence its progression. This could enable non-invasive monitoring of responses to treatment and also make it possible to look for complications after kidney transplantations. The use of EXs as therapeutics and vaccines seems to be safe and effective due to their target specificity and their lack of cytotoxicity. This and the fact that a specific cargo can be loaded into them also make them very promising candidates as novel drug delivery systems. This is still something of a challenge, however, and better protocols need to be developed. More research will be necessary to ensure the safety of the resulting medical applications.

A schematic overview of the signaling role of EXs in relation to the kidney is presented in Figure 2. It is known that EXs play a role in kidney diseases and renal cancer, but many of the signaling molecules found during nephrogenesis occur in association with EXs, leading us to conclude that they not only participate in disease processes but also play a putative role in developmental processes. Which machinery regulates these processes during embryonic kidney development still remains largely an open

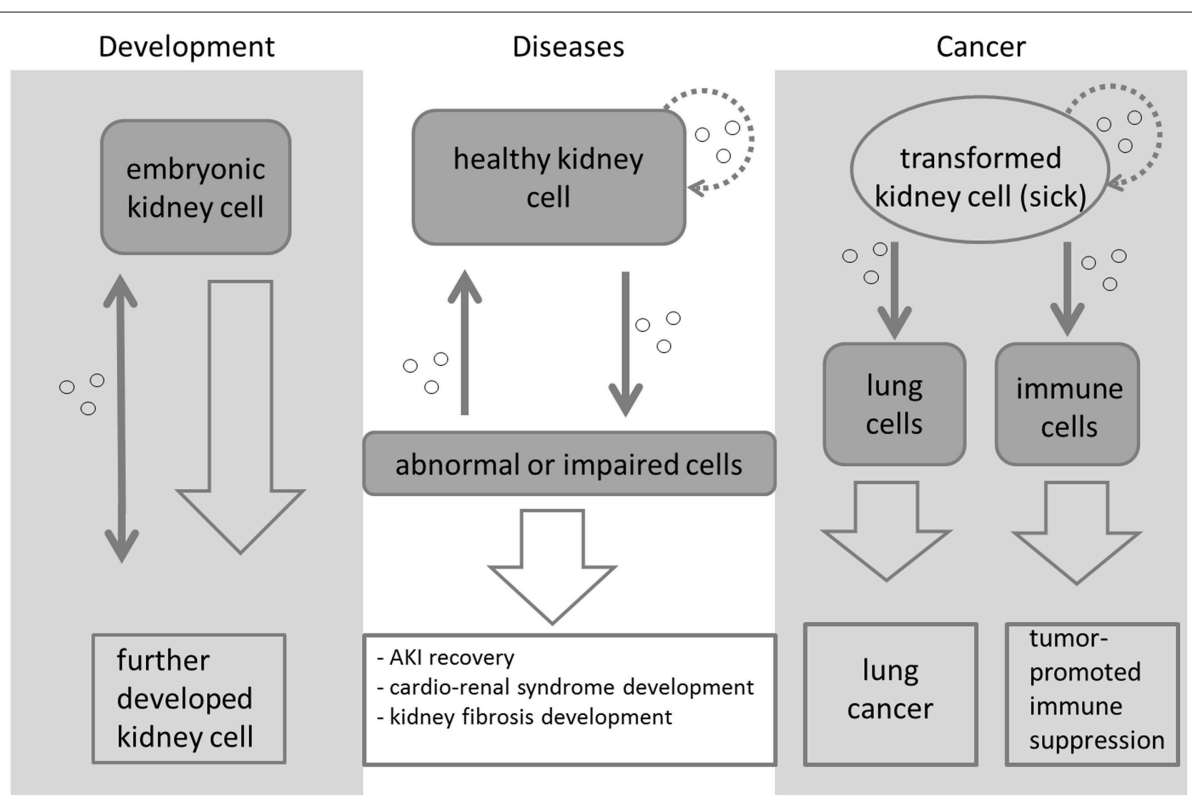

FIGURE 2 | Exosome-mediated signaling during kidney development, disease, and cancer. The signaling is symbolized by a thin gray arrow, while the development from one cell type/cell state to another is symbolized with a larger arrow. Different types of embryonic kidney cells release vesicles (small circles) to transfer signals during morphogenesis. These initiate and regulate the development of the organ. Exosomes are a means of cell-to-cell communication. When abnormal kidney conditions appear, exosomes can be released from the abnormal cells to be subsequently taken up by healthy cells, which will then be transformed and might even become abnormal as well. It has been reported that exosomes released from transformed kidney cells can initiate cancer in lung cells (Grange et al., 2011; Rana et al., 2012) and lead to tumor-promoted immune suppression in certain immune cells (Yang et al., 2013; Diao et al., 2015; Gu et al., 2015). Kidney cells and transformed kidney cells also take up the released vesicles again (dotted lined arrows). Most of the means of signaling depicted here are still not very well-characterized or understood. 
question, but the accumulating evidence is starting to point toward a critical role for EXs in inductive signaling in the kidney. Future work should be targeted toward elucidating the normal physiological roles of EXs in vivo in defined disease models and advancing our knowledge of the precise mechanisms by which they promote renal diseases and cancer.

\section{AUTHOR CONTRIBUTIONS}

MK drafted the manuscript and prepared the figures and tables. AS helped with writing the manuscript and designing the figures. AS and SV critically reviewed and revised the manuscript.

\section{REFERENCES}

Alvarez, S., Suazo, C., Boltansky, A., Ursu, M., Carvajal, D., Innocenti, G., et al. (2013). Urinary exosomes as a source of kidney dysfunction biomarker in renal transplantation. Transplant Proc. 45, 3719-3723. doi: 10.1016/j.transproceed.2013.08.079

Amabile, N., Guerin, A. P., Leroyer, A., Mallat, Z., Nguyen, C., Boddaert, J., et al. (2005). Circulating endothelial microparticles are associated with vascular dysfunction in patients with end-stage renal failure. J. Am. Soc. Nephrol. 16, 3381-3388. doi: 10.1681/asn.2005050535

Anderson, H. C., Mulhall, D., and Garimella, R. (2010). Role of extracellular membrane vesicles in the pathogenesis of various diseases, including cancer, renal diseases, atherosclerosis, and arthritis. Lab. Invest. 90, 1549-1557. doi: 10.1038/labinvest.2010.152

Arroyo, J. D., Chevillet, J. R., Kroh, E. M., Ruf, I. K., Pritchard, C. C., Gibson, D. F., Mitchell, P. S., et al. (2011). Argonaute2 complexes carry a population of circulating microRNAs independent of vesicles in human plasma. Proc. Natl. Acad. Sci. U.S.A. 108, 5003-5008. doi: 10.1073/pnas.1019055108

Azmi, A. S., Bao, B., and Sarkar, F. H. (2013). Exosomes in cancer development, metastasis, and drug resistance: a comprehensive review. Cancer Metastasis Rev. 32, 623-642. doi: 10.1007/s10555-013-9441-9

Barutta, F., Tricarico, M., Corbelli, A., Annaratone, L., Pinach, S., Grimaldi, S., et al. (2013). Urinary exosomal microRNAs in incipient diabetic nephropathy. PLoS ONE 8:e73798. doi: 10.1371/journal.pone.0073798

Ben-Dov, I. Z., Tan, Y. C., Morozov, P., Wilson, P. D., Rennert, H., Blumenfeld, J. D., et al. (2014). Urine microRNA as potential biomarkers of autosomal dominant polycystic kidney disease progression: description of miRNA profiles at baseline. PLoS ONE 9:e86856. doi: 10.1371/journal.pone.0086856

Biancone, L., Bruno, S., Deregibus, M. C., Tetta, C., and Camussi, G. (2012). Therapeutic potential of mesenchymal stem cell-derived microvesicles. Nephrol. Dial. Transplant. 27, 3037-3042. doi: 10.1093/ndt/gfs168

Blackwell, R. H., Franzen, C. A., Flanigan, R. C., Kuo, P. C., and Gupta, G. N. (2014). The untapped potential of urine shed bladder cancer exosomes: biomarkers, signaling, and therapeutics. Bladder 1, e7. doi: 10.14440/bladder.2014.38

Blanchard, N., Lankar, D., Faure, F., Regnault, A., Dumont, C., Raposo, G., et al. (2002). TCR activation of human T cells induces the production of exosomes bearing the TCR/CD3/zeta complex. J. Immunol. 168, 3235-3241. doi: 10.4049/jimmunol.168.7.3235

Borges, F., Reis, L., and Schor, N. (2013a). Extracellular vesicles: structure, function, and potential clinical uses in renal diseases. Braz. J. Med. Biol. Res. 46, 824-830. doi: 10.1590/1414-431X20132964

Borges, F. T., Melo, S. A., Ozdemir, B. C., Kato, N., Revuelta, I., Miller, C. A., et al. (2013b). TGF-betal-containing exosomes from injured epithelial cells activate fibroblasts to initiate tissue regenerative responses and fibrosis. J. Am. Soc. Nephrol. 24, 385-392. doi: 10.1681/ASN.2012101031

Boulanger, C. M., Amabile, N., Guerin, A. P., Pannier, B., Leroyer, A. S., Mallat, C. N., et al. (2007). In vivo shear stress determines circulating levels of endothelial microparticles in end-stage renal disease. Hypertension 49, 902-908. doi: 10.1161/01.HYP.0000259667.22309.df

Bruno, S., Grange, C., Collino, F., Deregibus, M. C., Cantaluppi, V., Biancone, L., et al. (2012). Microvesicles derived from mesenchymal stem cells enhance
All three authors read and approved final version of the manuscript.

\section{FUNDING}

This work was supported by the Academy of Finland (206038, 121647, 250900, and 260056), Centre of Excellence grant 2012-2017 of the Academy of Finland (251314), the Sigrid Jusélius Foundation and the European Community's Seventh Framework Program, FP7/2009, under grant agreement 305608 (EURenOmics: European Consortium for High-Throughput Research in Rare Kidney Diseases).

survival in a lethal model of acute kidney injury. PLOS ONE 7:e33115. doi: 10.1371/journal.pone.0033115

Bruno, S., Grange, C., Deregibus, M. C., Calogero, R. A., Saviozzi, S., Collino, F., Morando, L., et al. (2009). Mesenchymal stem cell-derived microvesicles protect against acute tubular injury. J. Am. Soc. Nephrol. 20, 1053-1067. doi: 10.1681/asn.2008070798

Camussi, G., Deregibus, M. C., Bruno, S., Cantaluppi, V., and Biancone, L. (2010). Exosomes/microvesicles as a mechanism of cell-to-cell communication. Kidney Int. 78, 838-848. doi: 10.1038/ki.2010.278

Cantaluppi, V., Gatti, S., Medica, D., Figliolini, F., Bruno, S., Deregibus, M. C., et al. (2012). Microvesicles derived from endothelial progenitor cells protect the kidney from ischemia-reperfusion injury by microRNAdependent reprogramming of resident renal cells. Kidney Int. 82, 412-427. doi: 10.1038/ki.2012.105

Carayon, K., Chaoui, K., Ronzier, E., Lazar, I., Bertrand-Michel, J., Roques, V., Balor, S., et al. (2011). Proteolipidic composition of exosomes changes during reticulocyte maturation. J. Biol. Chem. 286, 34426-34439. doi: 10.1074/jbc.m111.257444

Chairoungdua, A., Smith, D. L., Pochard, P., Hull, M., and Caplan, M. J. (2010). Exosome release of beta-catenin: a novel mechanism that antagonizes Wnt signaling. J. Cell Biol. 190, 1079-1091. doi: 10.1083/jcb.201002049

Chen, G., Zhang, Y., and Wu, X. (2014a). 786-0 Renal cancer cell line-derived exosomes promote 786-0 cell migration and invasion in vitro. Oncol. Lett. 7 , 1576-1580. doi: 10.3892/ol.2014.1962

Chen, H., Lai, P., Lan, Y., Cheng, C., Zhong, W., Lin, Y., et al. (2014b). Exosomal ATF3 RNA attenuates Pro-inflammatory gene MCP-1 transcription in renal ischemia-reperfusion. J. Cell. Physiol. 229, 1202-1211. doi: 10.1002/ jcp. 24554

Chen, L., Charrier, A., Zhou, Y., Chen, R., Yu, B., Agarwal, K., et al. (2014c). Epigenetic regulation of connective tissue growth factor by MicroRNA-214 delivery in exosomes from mouse or human hepatic stellate cells. Hepatology 59, 1118-1129. doi: 10.1002/hep.26768

Christianson, H. C., Svensson, K. J., van Kuppevelt, T. H., Li, J. P., and Belting, M. (2013). Cancer cell exosomes depend on cell-surface heparan sulfate proteoglycans for their internalization and functional activity. Proc. Natl. Acad. Sci. U.S.A. 110, 17380-17385. doi: 10.1073/pnas.1304266110

Colombo, M., Raposo, G., and Théry, C. (2014). Biogenesis, secretion, and intercellular interactions of exosomes and other extracellular vesicles. Annu. Rev. Cell Dev. Biol. 30, 255-289. doi: 10.1146/annurev-cellbio-101512-122326

Corbetta, S., Raimondo, F., Tedeschi, S., Syren, M. L., Rebora, P., Savoia, A., et al (2015). Urinary exosomes in the diagnosis of Gitelman and Bartter syndromes. Nephrol. Dial. Transplant. 30, 621-630. doi: 10.1093/ndt/gfu362

Dear, J. W., Street, J. M., and Bailey, M. A. (2013). Urinary exosomes: a reservoir for biomarker discovery and potential mediators of intrarenal signalling. Proteomics 13, 1572-1580. doi: 10.1002/pmic.201200285

Demory Beckler, M., Higginbotham, J. N., Franklin, J. L., Ham, A. J., Halvey, P. J., Imasuen, I. E., et al. (2013). Proteomic analysis of exosomes from mutant KRAS colon cancer cells identifies intercellular transfer of mutant KRAS. Mol. Cell. Proteomics 12, 343-355. doi: 10.1074/mcp.M112.022806

Denzer, K., van Eijk, M., Kleijmeer, M. J., Jakobson, E., de Groot, C., and Geuze, H. J. (2000). Follicular dendritic cells carry MHC class II-expressing microvesicles at their surface. J. Immunol. 165, 1259-1265. doi: 10.4049/jimmunol.165.3.1259 
Diao, J., Yang, X., Song, X., Chen, S., He, Y., Wang, Q., et al. (2015). Exosomal Hsp70 mediates immunosuppressive activity of the myeloid-derived suppressor cells via phosphorylation of Stat3. Med. Oncol. 32, 1-10. doi: 10.1007/s12032014-0453-2

Dimov, I., Jankovic Velickovic, L., and Stefanovic, V. (2009). Urinary exosomes. ScientificWorldJournal 9, 1107-1118. doi: 10.1100/tsw.2009.128

Dimuccio, V., Ranghino, A., Praticò Barbato, L., Fop, F., Biancone, L., Camussi, G., et al. (2014). Urinary CD133 extracellular vesicles are decreased in kidney transplanted patients with slow graft function and vascular damage. PLOS ONE 9:e104490. doi: 10.1371/journal.pone.0104490

Dorronsoro, A., and Robbins, P. D. (2013). Regenerating the injured kidney with human umbilical cord mesenchymal stem cell-derived exosomes. Stem Cell Res. Ther. 4, 39. doi: 10.1186/scrt187

Du, T., J. G., Wu, S., Cheng, Z., Cheng, J., and Zou, X. (2014). Microvesicles derived from human Wharton's jelly mesenchymal stem cells promote human renal cancer cell growth and aggressiveness through induction of hepatocyte growth factor. PLoS ONE9:e96836. doi: 10.1371/journal.pone.0096836

Eikmans, M., Baelde, H. J., Hagen, E. C., Paul, L. C., Eilers, P. H., De Heer, E., et al. (2003). Renal mRNA levels as prognostic tools in kidney diseases. J. Am. Soc. Nephrol. 14, 899-907. doi: 10.1097/01.asn.0000056611.92730.7b

Eliseeva, I., Kim, E., Guryanov, S., Ovchinnikov, L., and Lyabin, D. (2011). Ybox-binding protein 1 (YB-1) and its functions. Biochemistry (Moscow) 76, 1402-1433. doi: 10.1134/S0006297911130049

Escola, J. M., Kleijmeer, M. J., Stoorvogel, W., Griffith, J. M., Yoshie, O., and Geuze, H. J. (1998). Selective enrichment of tetraspan proteins on the internal vesicles of multivesicular endosomes and on exosomes secreted by human B-lymphocytes. J. Biol. Chem. 273, 20121-20127. doi: 10.1074/jbc.273.32.20121

Fang, D. Y., King, H. W., Li, J. Y., and Gleadle, J. M. (2013). Exosomes and the kidney: blaming the messenger. Nephrology 18, 1-10. doi: 10.1111/nep.12005

Faure, V., Dou, L., Sabatier, F., Cerini, C., Sampol, J., Berland, Y., et al. (2006). Elevation of circulating endothelial microparticles in patients with chronic renal failure. J. Thromb. Haemost. 4, 566-573. doi: 10.1111/j.15387836.2005.01780.x

Feng, D., Zhao, W., Ye, Y., Bai, X., Liu, R., Chang, L., et al. (2010). Cellular internalization of exosomes occurs through phagocytosis. Traffic 11, 675-687. doi: 10.1111/j.1600-0854.2010.01041.x

Fitzner, D., Schnaars, M., van Rossum, D., Krishnamoorthy, G., Dibaj, P., Bakhti, M., et al. (2011). Selective transfer of exosomes from oligodendrocytes to microglia by macropinocytosis. J. Cell. Sci. 124, 447-458. doi: 10.1242/jcs.074088

Fong, M. Y., Zhou, W., Liu, L., Alontaga, A. Y., Chandra, M., Ashby, J., et al. (2015). Breast-cancer-secreted miR-122 reprograms glucose metabolism in premetastatic niche to promote metastasis. Nat. Cell Biol. 17, 183-194. doi: $10.1038 /$ ncb3094

Gatti, S., Bruno, S., Deregibus, M. C., Sordi, A., Cantaluppi, V., Tetta, C., et al. (2011). Microvesicles derived from human adult mesenchymal stem cells protect against ischaemia-reperfusion-induced acute and chronic kidney injury. Nephrol. Dial. Transplant. 26, 1474-1483. doi: 10.1093/ndt/gfr015

Gildea, J. J., Seaton, J. E., Victor, K. G., Reyes, C. M., Wang, D. B., Pettigrew, A. C., et al. (2014). Exosomal transfer from human renal proximal tubule cells to distal tubule and collecting duct cells. Clin. Biochem. 47, 89-94. doi: 10.1016/j.clinbiochem.2014.06.018

Gonzales, P. A., Pisitkun, T., Hoffert, J. D., Tchapyjnikov, D., Star, R. A., Kleta, R., et al. (2009). Large-scale proteomics and phosphoproteomics of urinary exosomes. J. Am. Soc. Nephrol. 20, 363-379. doi: 10.1681/asn.2008040406

Gonzalez-Calero, L., Martin-Lorenzo, M., and Alvarez-Llamas, G. (2014). Exosomes: a potential key target in cardio-renal syndrome. Front. Immunol. 5:465. doi: 10.3389/fimmu.2014.00465

Grange, C., Collino, F., Tapparo, M., and Camussi, G. (2014). Oncogenic microRNAs and renal cell carcinoma. Front. Oncol. 4:49. doi: 10.3389/fonc.2014. 00049

Grange, C., Tapparo, M., Collino, F., Vitillo, L., Damasco, C., Deregibus, M. C., et al. (2011). Microvesicles released from human renal cancer stem cells stimulate angiogenesis and formation of lung premetastatic niche. Cancer Res. 71, 5346-5356. doi: 10.1158/0008-5472.CAN-11-0241

Greening, D. W., Gopal, S. K., Xu, R., Simpson, R. J., and Chen, W. (2015). Exosomes and their roles in immune regulation and cancer. Semin. Cell Dev. Biol. 40, 72-81. doi: 10.1016/j.semcdb.2015.02.009
Gu, X., Erb, U., Büchler, M. W., and Zöller, M. (2015). Improved vaccine efficacy of tumor exosome compared to tumor lysate loaded dendritic cells in mice. Int. J. Cancer 136, E74-E84. doi: 10.1002/ijc.29100

Hanson, P. I., and Cashikar, A. (2012). Multivesicular body morphogenesis. Annu. Rev. Cell Dev. Biol. 28, 337-362. doi: 10.1146/annurev-cellbio-092910-154152

Henne, W. M., Stenmark, H., and Emr, S. D. (2013). Molecular mechanisms of the membrane sculpting ESCRT pathway. Cold Spring Harb Perspect. Biol. 5:a016766. doi: 10.1101/cshperspect.a016766

Jiang, X. L., Zhang, Y., Tan, B., Luo, C. L., and Wu, X. H. (2014). Renal tumorderived exosomes inhibit hepaCAM expression of renal carcinoma cells in a pAKT-dependent manner. Neoplasma 61, 416-423. doi: 10.4149/neo_2014_051

Johnsen, K. B., Gudbergsson, J. M., Skov, M. N., Pilgaard, L., Moos, T., and Duroux, M. (2014). A comprehensive overview of exosomes as drug delivery vehiclesEndogenous nanocarriers for targeted cancer therapy. Biochim. Biophys. Acta 1846, 75-87. doi: 10.1016/j.bbcan.2014.04.005

Kalani, A., Mohan, A., Godbole, M. M., Bhatia, E., Gupta, A., Sharma, R. K., et al. (2013). Wilm's tumor-1 protein levels in urinary exosomes from diabetic patients with or without proteinuria. PLOS ONE 8:e60177. doi: 10.1371/journal.pone.0060177

Knepper, M., and Pisitkun, T. (2007). Exosomes in urine: who would have thought. . . ?. Kidney Int. 72, 1043-1045. doi: 10.1038/sj.ki.5002510

Koppers-Lalic, D., Hackenberg, M., Bijnsdorp, I. V., van Eijndhoven, M. A., Sadek, P., Sie, D., et al. (2014). Nontemplated nucleotide additions distinguish the small RNA composition in cells from exosomes. Cell Rep. 8, 1649-1658. doi: 10.1016/j.celrep.2014.08.027

Kowal, J., Tkach, M., and Thery, C. (2014). Biogenesis and secretion of exosomes. Curr. Opin. Cell Biol. 29, 116-125. doi: 10.1016/j.ceb.2014.05.004

Krause, M., Rak-Raszewska, A., Pietilä, I., Quaggin, S. E., and Vainio, S. (2015). Signaling during kidney development. Cells 4, 112-132. doi: $10.3390 /$ cells 4020112

Kwon, S., Liu, K. D., and Mostov, K. E. (2014). Intercellular transfer of GPRC5B via exosomes drives HGF-mediated outward growth. Curr. Biol. 24, 199-204. doi: 10.1016/j.cub.2013.12.010

Lee, T. H., D’Asti, E., Magnus, N., Al-Nedawi, K., Meehan, B., and Rak, J. (2011). Microvesicles as mediators of intercellular communication in cancer-the emerging science of cellular 'debris'. Semin. Immunopathol. 33, 455-467. doi: 10.1007/s00281-011-0250-3

Liang, B., Peng, P., Chen, S., Li, L., Zhang, M., Cao, D., et al. (2013). Characterization and proteomic analysis of ovarian cancer-derived exosomes. J. Proteomics 80, 171-182. doi: 10.1016/j.jprot.2012.12.029

Lu, Q., Zhang, J., Allison, R., Gay, H., Yang, W., Bhowmick, N. A., et al. (2009). Identification of extracellular $\delta$-catenin accumulation for prostate cancer detection. Prostate 69, 411-418. doi: 10.1002/pros.20902

Lv, L., Cao, Y., Pan, M., Liu, H., Tang, R., Ma, K., et al. (2014). CD2AP mRNA in urinary exosome as biomarker of kidney disease. Clin. Chim. Acta 428, 26-31. doi: 10.1016/j.cca.2013.10.003

Lv, L. L., Cao, Y. H., Ni, H. F., Xu, M., Liu, D., Liu, H., et al. (2013). MicroRNA-29c in urinary exosome/microvesicle as a biomarker of renal fibrosis. Am. J. Physiol. Renal Physiol. 305, F1220-F1227. doi: 10.1152/ajprenal.00148.2013

Mathivanan, S., and Simpson, R. J. (2009). ExoCarta: a compendium of exosomal proteins and RNA. Proteomics 9, 4997-5000. doi: 10.1002/pmic.2009 00351

Melo, S. A., Luecke, L. B., Kahlert, C., Fernandez, A. F., Gammon, S. T., Kaye, J., et al. (2015). Glypican-1 identifies cancer exosomes and detects early pancreatic cancer. Nature 523, 177-182. doi: 10.1038/nature14581

Minciacchi, V. R., Freeman, M. R., and Di Vizio, D. (2015). Extracellular vesicles in cancer: exosomes, microvesicles and the emerging role of large oncosomes. Semin. Cell Dev. Biol. 40, 41-51. doi: 10.1016/j.semcdb.2015.02.010

Miranda, K. C., Bond, D. T., McKee, M., Skog, J., Pãunescu, T. G., Da Silva, N., et al. (2010). Nucleic acids within urinary exosomes/microvesicles are potential biomarkers for renal disease. Kidney Int. 78, 191-199. doi: 10.1038/ki.2010.106

Mitchell, P. J., Welton, J., Staffurth, J., Mason, M. D., Tabi, Z., and Clayton, A. (2009). Can urinary exosomes act as treatment response markers in prostate cancer. J. Transl. Med. 7:4. doi: 10.1186/1479-5876-7-4

Mittelbrunn, M., Gutiérrez-Vázquez, C., Villarroya-Beltri, C., González, S., Sánchez-Cabo, F., González, M. Á., et al. (2011). Unidirectional transfer of microRNA-loaded exosomes from T cells to antigen-presenting cells. Nat. Commun. 2:282. doi: $10.1038 /$ ncomms 1285 
Montecalvo, A., Larregina, A. T., Shufesky, W. J., Stolz, D. B., Sullivan, M. L., Karlsson, J. M., Baty, C. J., et al. (2012). Mechanism of transfer of functional microRNAs between mouse dendritic cells via exosomes. Blood 119, 756-766. doi: 10.1182/blood-2011-02-338004

Morelli, A. E., Larregina, A. T., Shufesky, W. J., Sullivan, M. L., Stolz, D. B., Papworth, G. D., Zahorchak, A. F., et al. (2004). Endocytosis, intracellular sorting, and processing of exosomes by dendritic cells. Blood 104, 3257-3266. doi: 10.1182/blood-2004-03-0824

Mulcahy, L. A., Pink, R. C., and Carter, D. R. F. (2014). Routes and mechanisms of extracellular vesicle uptake. J. Extracell. Vesicles 3:24641. doi: 10.3402/jev.v3. 24641

Musante, L., Tataruch, D. E., and Holthofer, H. (2014). Use and isolation of urinary exosomes as biomarkers for diabetic nephropathy. Front. Endocrinol. 5:149. doi: 10.3389/fendo.2014.00149

Nagasawa, M., Koide, H., Ohsawa, K., and Hoshi, T. (1992). Purification of bursh border membrane vesicles from rat renal cortex by sizeexclusion chromatography. Anal. Biochem. 201, 301-305. doi: 10.1016/00032697(92)90342-5

Neal, C. S., Michael, M. Z., Pimlott, L. K., Yong, T. Y., Li, J. Y., and Gleadle, J. M. (2011). Circulating microRNA expression is reduced in chronic kidney disease. Nephrol. Dial. Transplant. 26, 3794-3802. doi: 10.1093/ndt/gfr485

Nieto, M. A. (2011). The ins and outs of the epithelial to mesenchymal transition in health and disease. Annu. Rev. Cell Dev. Biol. 27, 347-376. doi: 10.1146/annurev-cellbio-092910-154036

Nolte-'t Hoen, E. N., Buschow, S. I., Anderton, S. M., Stoorvogel, W., and Wauben, M. H. (2009). Activated T cells recruit exosomes secreted by dendritic cells via LFA-1. Blood 113, 1977-1981. doi: 10.1182/blood-2008-08-174094

Pan, B., and Johnstone, R. M. (1983). Fate of the transferrin receptor during maturation of sheep reticulocytes in vitro: selective externalization of the receptor. Cell 33, 967-978. doi: 10.1016/0092-8674(83)90040-5

Parolini, I., Federici, C., Raggi, C., Lugini, L., Palleschi, S., De Milito, A., Coscia, C., et al. (2009). Microenvironmental $\mathrm{pH}$ is a key factor for exosome traffic in tumor cells. J. Biol. Chem. 284, 34211-34222. doi: 10.1074/jbc.m109. 041152

Pegtel, D. M., Cosmopoulos, K., Thorley-Lawson, D. A., van Eijndhoven, M. A., Hopmans, E. S., Lindenberg, J. L., et al. (2010). Functional delivery of viral miRNAs via exosomes. Proc. Natl. Acad. Sci. U.S.A. 107, 6328-6333. doi: 10.1073/pnas.0914843107

Peinado, H., Aleèkoviæ, M., Lavotshkin, S., Matei, I., Costa-Silva, B., MorenoBueno, G., et al. (2012). Melanoma exosomes educate bone marrow progenitor cells toward a pro-metastatic phenotype through MET. Nat. Med. 18, 883-891. doi: $10.1038 / \mathrm{nm} .2753$

Pisitkun, T., Shen, R. F., and Knepper, M. A. (2004). Identification and proteomic profiling of exosomes in human urine. Proc. Natl. Acad. Sci. U.S.A. 101, 13368-13373. doi: 10.1073/pnas.0403453101

Properzi, F., Logozzi, M., and Fais, S. (2013). Exosomes: the future of biomarkers in medicine. Biomark. Med. 7, 769-778. doi: 10.2217/bmm.13.63

Rana, S., Yue, S., Stadel, D., and Zöller, M. (2012). Toward tailored exosomes: the exosomal tetraspanin web contributes to target cell selection. Int. J. Biochem. Cell Biol. 44, 1574-1584. doi: 10.1016/j.biocel.2012.06.018

Ranghino, A., Dimuccio, V., Papadimitriou, E., and Bussolati, B. (2014). Extracellular vesicles in the urine: markers and mediators of tissue damage and regeneration. Clin. Kidney J. 8, 23-30. doi: 10.1093/ckj/sfu136

Raposo, G., and Stoorvogel, W. (2013). Extracellular vesicles: exosomes, microvesicles, and friends. J. Cell Biol. 200, 373-383. doi: 10.1083/jcb.2012 11138

Raposo, G., Tenza, D., Mecheri, S., Peronet, R., Bonnerot, C., and Desaymard, C. (1997). Accumulation of major histocompatibility complex class II molecules in mast cell secretory granules and their release upon degranulation. Mol. Biol. Cell 8, 2631-2645. doi: 10.1091/mbc.8.12.2631

Reinhardt, T. A., Sacco, R. E., Nonnecke, B. J., and Lippolis, J. D. (2013). Bovine milk proteome: quantitative changes in normal milk exosomes, milk fat globule membranes and whey proteomes resulting from Staphylococcus aureus mastitis. J. Proteomics 82, 141-154. doi: 10.1016/j.jprot.2013.02.013

Reis, L. A., Borges, F. T., Simoes, M. J., Borges, A. A., Sinigaglia-Coimbra, R., and Schor, N. (2012). Bone marrow-derived mesenchymal stem cells repaired but did not prevent gentamicin-induced acute kidney injury through paracrine effects in rats. PLoS ONE 7:e44092. doi: 10.1371/journal.pone.0044092
Salih, M., Zietse, R., and Hoorn, E. J. (2014). Urinary extracellular vesicles and the kidney: biomarkers and beyond. Am. J. Physiol. Renal Physiol. 306, F1251-F1259. doi: 10.1152/ajprenal.00128.2014

Skog, J., Würdinger, T., van Rijn, S., Meijer, D. H., Gainche, L., Curry, W. T., et al. (2008). Glioblastoma microvesicles transport RNA and proteins that promote tumour growth and provide diagnostic biomarkers. Nat. Cell Biol. 10, 1470-1476. doi: 10.1038/ncb1800

Skogberg, G., Gudmundsdottir, J., van der Post, S., Sandström, K., Bruhn, S., Benson, M., et al. (2013). Characterization of human thymic exosomes. PLoS ONE 8:e67554. doi: 10.1371/journal.pone.0067554

Smalley, D. M., Sheman, N. E., Nelson, K., and Theodorescu, D. (2008). Isolation and identification of potential urinary microparticle biomarkers of bladder cancer. J. Proteome Res. 7, 2088-2096. doi: 10.1021/pr700775x

Stoorvogel, W., Kleijmeer, M. J., Geuze, H. J., and Raposo, G. (2002). The biogenesis and functions of exosomes. Traffic 3, 321-330. doi: 10.1034/j.16000854.2002.30502.x

Stoorvogel, W. (2012). Functional transfer of microRNA by exosomes. Blood 119, 646-648. doi: 10.1182/blood-2011-11-389478

Street, J. M., Birkhoff, W., Menzies, R. I., Webb, D. J., Bailey, M. A., and Dear, J. W. (2011). Exosomal transmission of functional aquaporin 2 in kidney cortical collecting duct cells. J. Physiol. 589, 6119-6127. doi: 10.1113/jphysiol.2011.220277

Suntres, Z. E., Smith, M. G., Momen-Heravi, F., Hu, J., Zhang, X., Wu, Y., et al. (2013). Therapeutic uses of exosomes. Exosomes Microvesicles 1, 1-8. doi: $10.5772 / 56522$

Svensson, K. J., Christianson, H. C., Wittrup, A., Bourseau-Guilmain, E., Lindqvist, E., Svensson, L. M., et al. (2013). Exosome uptake depends on ERK1/2-heat shock protein 27 signaling and lipid Raft-mediated endocytosis negatively regulated by caveolin-1. J. Biol. Chem. 288, 17713-17724. doi: 10.1074/jbc.m112.445403

Tang, F., Kaneda, M., O'Carroll, D., Hajkova, P., Barton, S. C., Sun, Y. A., et al. (2007). Maternal microRNAs are essential for mouse zygotic development. Genes Dev. 21, 644-648. doi: 10.1101/gad.418707

Tauro, B. J., Mathias, R. A., Greening, D. W., Gopal, S. K., Ji, H., Kapp, E. A., Coleman, B. M., et al. (2013). Oncogenic H-ras reprograms MadinDarby canine kidney (MDCK) cell-derived exosomal proteins following epithelial-mesenchymal transition. Mol. Cell. Proteomics 12, 2148-2159. doi: 10.1074/mcp.m112.027086

Théry, C., Ostrowski, M., and Segura, E. (2009). Membrane vesicles as conveyors of immune responses. Nat. Rev. Immunol. 9, 581-593. doi: 10.1038/nri2567

Théry, C., Zitvogel, L., and Amigorena, S. (2002). Exosomes: composition, biogenesis and function. Nat. Rev. Immunol. 2, 569-579. doi: 10.1038/nri855

Tian, T., Zhu, Y. L., Zhou, Y. Y., Liang, G. F., Wang, Y. Y., Hu, F. H., et al. (2014). Exosome uptake through clathrin-mediated endocytosis and macropinocytosis and mediating miR-21 delivery. J. Biol. Chem. 289, 22258-22267. doi: $10.1074 /$ jbc.m114.588046

Tomasoni, S., Longaretti, L., Rota, C., Morigi, M., Conti, S., Gotti, E., et al. (2012). Transfer of growth factor receptor mRNA via exosomes unravels the regenerative effect of mesenchymal stem cells. Stem Cells Dev. 22, 772-780. doi: $10.1089 /$ scd.2012.0266

Urbanelli, L., Magini, A., Buratta, S., Brozzi, A., Sagini, K., Polchi, A., et al. (2013). Signaling pathways in exosomes biogenesis, secretion and fate. Genes 4, 152-170. doi: 10.3390/genes4020152

Valadi, H., Ekström, K., Bossios, A., Sjöstrand, M., Lee, J. J., and Lötvall, J. O. (2007). Exosome-mediated transfer of mRNAs and microRNAs is a novel mechanism of genetic exchange between cells. Nat. Cell Biol. 9, 654-659. doi: $10.1038 /$ ncb 1596

van Balkom, B. W., Pisitkun, T., Verhaar, M. C., and Knepper, M. A. (2011). Exosomes and the kidney: prospects for diagnosis and therapy of renal diseases. Kidney Int. 80, 1138-1145. doi: 10.1038/ki.2011.292

van Koppen, A., Joles, J. A., Van Balkom, B., Lim, S. K., de Kleijn, D., Giles, R. H., et al. (2012). Human embryonic mesenchymal stem cell-derived conditioned medium rescues kidney function in rats with established chronic kidney disease. PLoS ONE 7:e38746. doi: 10.1371/journal.pone.0038746

Vickers, K. C., Palmisano, B. T., Shoucri, B. M., Shamburek, R. D., and Remaley, A. T. (2011). MicroRNAs are transported in plasma and delivered to recipient cells by high-density lipoproteins. Nat. Cell Biol. 13, 423-433. doi: 10.1038/ ncb2210 
Vishnubhatla, I., Corteling, R., Stevanato, L., Hicks, C., and Sinden, J. (2014). The development of stem cell-derived exosomes as a cell-free regenerative medicine. J. Circ. Biomark 143, 2. doi: 10.5772/58597

Wels, J., Kaplan, R. N., Rafii, S., and Lyden, D. (2008). Migratory neighbors and distant invaders: tumor-associated niche cells. Genes Dev. 22, 559-574. doi: 10.1101/gad.1636908

White, I. J., Bailey, L. M., Aghakhani, M. R., Moss, S. E., and Futter, C. E. (2006). EGF stimulates annexin 1-dependent inward vesiculation in a multivesicular endosome subpopulation. EMBO J. 25, 1-12. doi: 10.1038/sj.emboj.7600759

Yanez-Mo, M., Siljander, P. R., Andreu, Z., Zavec, A. B., Borras, F. E., Buzas, E. I., Buzas, K., et al. (2015). Biological properties of extracellular vesicles and their physiological functions. J. Extracell Vesicles 4:27066. doi: 10.3402/jev.v4.27066

Yang, L., Wu, X., Wang, D., Luo, C., and Chen, L. (2013). Renal carcinoma cellderived exosomes induce human immortalized line of Jurkat $\mathrm{T}$ lymphocyte apoptosis in vitro. Urol. Int. 91, 363-369. doi: 10.1159/000348747

Zhang, B., Wang, M., Gong, A., Zhang, X., Wu, X., Zhu, Y., et al. (2015a). HucMSC-exosome mediated-Wnt4 signaling is required for cutaneous wound healing. Stem Cells 33, 2158-2168. doi: 10.1002/stem.1771

Zhang, J., Li, S., Li, L., Li, M., Guo, C., Yao, J., et al. (2015b). Exosome and exosomal microRNA: trafficking, sorting, and function. Genomics Proteomics Bioinformatics 13, 17-24. doi: 10.1016/j.gpb.2015.02.001

Zhang, L., Wu, X., Luo, C., Chen, X., Yang, L., Tao, J., et al. (2013). The 786-0 renal cancer cell-derived exosomes promote angiogenesis by downregulating the expression of hepatocyte cell adhesion molecule. Mol. Med. Rep. 8, 272-276. doi: $10.3892 / \mathrm{mmr} .2013 .1458$

Zhang, Y., Luo, C., He, B., Zhang, J., Cheng, G., Wu, X., et al. (2010). Exosomes derived from IL-12-anchored renal cancer cells increase induction of specific antitumor response in vitro: a novel vaccine for renal cell carcinoma. Int. J. Oncol. 36, 133-140. doi: 10.3892/ijo_00000484

Zhou, H., Cheruvanky, A., Hu, X., Matsumoto, T., Hiramatsu, N., Cho, M. E., et al. (2008). Urinary exosomal transcription factors, a new class of biomarkers for renal disease. Kidney Int. 74, 613-621. doi: 10.1038/ki.2008.206
Zhou, H., Kajiyama, H., Tsuji, T., Hu, X., Leelahavanichkul, A., Vento, S., Frank, R., et al. (2013b). Urinary exosomal Wilms' tumor-1 as a potential biomarker for podocyte injury. Am. J. Physiol. Renal Physiol. 305, F553-F559. doi: 10.1152/ajprenal.00056.2013

Zhou, H., Pisitkun, T., Aponte, A., Yuen, P. S., Hoffert, J. D., Yasuda, H., et al. (2006). Exosomal Fetuin-A identified by proteomics: a novel urinary biomarker for detecting acute kidney injury. Kidney Int. 70, 1847-1857. doi: 10.1038/sj.ki.5001874

Zhou, Y., Xu, H., Xu, W., Wang, B., Wu, H., Tao, Y., et al. (2013a). Exosomes released by human umbilical cord mesenchymal stem cells protect against cisplatin-induced renal oxidative stress and apoptosis in vivo and in vitro. Stem Cell Res. Ther. 4, 34. doi: 10.1186/scrt194

Zitvogel, L., Regnault, A., Lozier, A., Wolfers, J., Flament, C., Tenza, D., et al. (1998). Eradication of established murine tumors using a novel cellfree vaccine: dendritic cell derived exosomes. Nat. Med. 4, 594-600. doi: 10.1038/nm0598-594

Zubiri, I., Posada-Ayala, M., Sanz-Maroto, A., Calvo, E., Martin-Lorenzo, M., Gonzalez-Calero, L., et al. (2014). Diabetic nephropathy induces changes in the proteome of human urinary exosomes as revealed by label-free comparative analysis. J. Proteomics 96, 92-102. doi: 10.1016/j.jprot.2013. 10.037

Conflict of Interest Statement: The authors declare that the research was conducted in the absence of any commercial or financial relationships that could be construed as a potential conflict of interest.

Copyright $\odot 2015$ Krause, Samoylenko and Vainio. This is an open-access article distributed under the terms of the Creative Commons Attribution License (CC BY). The use, distribution or reproduction in other forums is permitted, provided the original author(s) or licensor are credited and that the original publication in this journal is cited, in accordance with accepted academic practice. No use, distribution or reproduction is permitted which does not comply with these terms. 